\title{
UNIVERSITY ACADEMICS RESPONDING AND ADJUSTING TO THE INCREASING NUMBERS OF CROSS CULTURAL AND OVERSEAS STUDENTS
}

\section{J PHILLIPS*}

This article draws on material gathered during the conduct of two research projects. The first project investigated the nature of the primary determinants of study success for Indonesian Post Graduate students studying in Australian universities. This project was sponsored by the Australian International Development Assistance Bureau (AIDAB). The second study entitled Research into the Professional Development of Tertiary Teaching for Academics: With Special Reference to Cross Cultural and Overseas Student Interaction, investigates the nature of the reaction of academics to the increasing number of cross cultural and overseas students attending their courses. This project, was funded by the Department of Employment, Education and Training (DEET). The article draws on the data gathered in the above studies and explores the nature of the change which has occurred in the student body of Australian universities and suggests the reasons why many academics are modifying the way they teach students.

\section{THE NEW FACE OF UNIVERSITY EDUCATION}

Changes instituted by $\mathrm{Mr}$ Dawkins, the former Minister for Employment, Education and Training of the Australian Federal Government, have radically altered the structure and composition of university education in Australia, so much so that both the previously constituted universities and CAEs have struggled to understand and adjust to the new requirements and expectations. 
Nevertheless, no matter how radical such changes may have been considered, other changes, such as the types of students now attending universities, are also having a profound influence on the process of higher education. Not only are there increased numbers of students, and therefore, larger classes, but also the composition of the students who attend those classes is radically different. Many such students now increasingly come from cross cultural and overseas backgrounds, speak other languages and have had different educational upbringings.

\section{THE FULL FEE PAYING POLICY}

In 1985 it was observed that although the Services constituted $74 \%$ of Australia's GNP, they were only responsible for $4 \%$ of export earning. It was also noted that before this time, despite Australia's long tradition of educating overseas students, the Educational Sector had not engaged in exporting its services.

In 1985, the Australian Government sent an education mission to various Asian countries to investigate the commercial opportunities for the marketing of Australian university education. The mission reported that significant areas of demand for educational services did exist and could be met by the Australian educational sector. It was estimated that by 1988, provided effective marketing strategies were employed, educational services and related activities could annually amount to approximately $\$ 100 \mathrm{~m}$ in foreign exchange earnings. This figure was later found to be an under estimation of potential earnings. By 1989 direct fee earnings were calculated to be $\$ 318 \mathrm{~m},{ }^{1}$ with total expenditures on other items such as accommodation, transport, and so forth, to amount to two or three times that figure.

\section{THE CHANGING FACE OF THE STUDENT BODY}

DEET information indicates that "in just four years to mid1989 it (the overseas student body) rose from 24,000 to 55,500.”2 It should be noted that only one one third of these students were taking a full-fee course, others were taking informal courses. This combined total had progressively increased since 1986 - 23,833, 1987 - 29,121, 1988 - 43,979. 


\section{HOME RESIDENCE OF STUDENTS}

Statistics provided by DEET (see tables 1 to 4 ) indicated that in 199028,311 students of the total 485,077 university population identified an overseas county as their home residence. If those 893 students coming from the USA and New Zealand, which are predominantly English speaking countries, are deducted, the remaining 27,418 students represented a group of students who came from, and would be returning to, mostly Asian countries in which English is spoken as a foreign language, and where the legal, cultural and educational practices are quite different to those practised in Australia.

\section{THE NESB OR CCS/OS STUDENT}

Where the number of university students, however, in the DEET statistics, has been broken down according to county of birth, the figures which refer to the top 10 countries indicate that 78,110 students come from a NESB country.

The term NESB is defined as students who have migrated to Australia or are the children of parents who have come to Australia and whose first language is a language other than English. ${ }^{3}$

The 78,110 NESB student figure indicates that the "overseas student" classificatory term, referred to above, might hide the true nature of the cross cultural student population in universities. A more embracing term might be that of "cross cultural students/overseas students" (CCS/OS), since the difficulties experienced by "overseas students” are generally indistinguishable from local migrant, or "cross cultural students". The figure of 78,011 is $16 \%$ of the total 485,077 of university students in Australia.

Table 1: 1990 Overseas Students by Home Residence (top 10 countries)

\begin{tabular}{|clc|}
\hline 1 & Malaysia & 6669 \\
2 & Hong Kong & 3716 \\
3 & Indonesia & 1868 \\
\hline
\end{tabular}




\begin{tabular}{|clc|}
\hline 4 & China & 1216 \\
5 & Fiji & 561 \\
6 & Thailand & 552 \\
7 & USA & 539 \\
8 & NZ & 354 \\
9 & Taiwan & 339 \\
10 & Singapore & 285 \\
\hline
\end{tabular}

The total overseas student population by home residence is $28,311 .^{4}$

The following tables give more data on countries of origin.

Table $2^{5}$ : 1990 Overseas Students by Country of Birth

\begin{tabular}{|l|llr|}
\hline If only NESB & 1 & Australia & 374,146 \\
countries included & 2 & UK & 24,184 \\
from the top 10, the & 3 & Malaysia & 12,105 \\
combined total is & 4 & NZ & 5,871 \\
78,011 or 16\% or & 5 & Vietnam & 5,490 \\
overall. Of this total & 6 & Singapore & 4,370 \\
35\%, or 27, 418 & 7 & Indonesia & 2,956 \\
identify an overseas & 8 & USA & 2,766 \\
address in an NESB & 9 & China & 2,713 \\
country. & 10 & India & 2,134 \\
& \multicolumn{3}{|l}{ Total Number of University students $=485,077$} \\
\hline
\end{tabular}

These tables indicate the origins, and therefore cultural derivations of many of these students.

By 1989 the majority of overseas university students were said to be coming from Asian countries. Searle and Brash state that in "In-mid 1989, 30,135 of the total 32,198 full fee students came from Asia.”6

Table $3^{7}$ : Number of Institutions Offering Approved Full Fee Course to Overseas Students Between 1986 and 1990

\begin{tabular}{|lllll|}
\hline 1986 & 1987 & 1988 & 1989 & 1990 \\
\hline
\end{tabular}




\begin{tabular}{|lccccc|}
\hline High Education & 22 & 51 & 60 & 63 & 113 \\
$\begin{array}{l}\text { Technical and } \\
\text { Further Education } \\
\text { (TAFE) }\end{array}$ & 11 & 17 & 20 & $20(\mathrm{C})$ & \\
Schools & & & & & \\
English Language & 19 & 29 & 62 & 91 & 103 \\
$\begin{array}{l}\text { Intensive Courses } \\
\text { for Overseas }\end{array}$ & & & & & \\
$\begin{array}{l}\text { Students } \\
\text { (ELICOS) }\end{array}$ & & & & & \\
Special Studies & 173 & 210 & 251 & 298 & 200 \\
\hline
\end{tabular}

\section{A MAJOR SHIFT IN THE CHARACTER OF THE STUDENT POPULATION}

From these figures it can be concluded that by far the majority of students, (65\%) who come from a NESB background, will continue to be part of the Australian population. It is evident, therefore, that there has been a major shift in the character of the university student population, from one of the primarily AngloCeltic, English speaking origins, to one which also includes a large and increasing percentage of students who come from a NESB background.

It should be added here that these figures are only approximate and that the true figure of CCS/OS might be closer to $20 \%$ of the student population. Also, several leading academics have expressed the opinion that the current numbers of overseas students will possibly double in the foreseeable future.

\section{Responses to Changes in the Ethnic Composition of Students in Other Education Systems}

When the number or NESB students in primary and secondary schools in Australia was identified initially at 20\%, and later at 25\%, the various Federal and State Education Departments instituted programs of retraining for teachers. ${ }^{8}$ These activities continue to the present time. The education departments realised that since the character of the student population in schools had 
radically changed, there was a need, on the one hand, to give special assistance to these students so that they could meet the requirements of the educational process, while on the other hand, it was recognised that the teachers in the various curricular areas also needed retraining so that they might better respond to the multicultural nature of their student population.

\section{Responses in the University Sector}

With respect to the change in the character of the student body in university institutions, apart from the provision of more English instruction for some of the students, for which the students generally pay fees, there has been little recognition by the universities of the fact that academic and support staff require retraining in order to more adequately respond to the special needs of the cross cultural and overseas students (CCS/OS).

\section{What and Where CCS/OS Study}

The figures presented in Table 4 demonstrates that, unlike the primary and secondary education settings, in which the majority of CCS/OS tend to be scattered across the schools of the capital cities, the CCS/OS in universities tend to be grouped into a limited number of Universities and, more importantly, in a limited number of disciplines. Such areas are undergraduate (76\%) and masters degrees (7.6\%) in the disciplines of Business Administration and Economics (50\%), Sciences (14\%), Arts, Humanities and Social Science (9\%), Engineering/Surveying (5\%), and Health (7\%), in that order. Other CCS/OS are taking studies in other fields. The current statistical insignificance of law students is notable, although CCS/OS students take law subjects from within other disciplines. Such a finding might represent a further opportunity for the export of education.

With respect to where most CCS/OS go to obtain their university degrees, Table 4 identifies the top 10 universities attracting the majority of students in 1990.

Table $4^{9}$ : Total Overseas Students by University of Choice (most popular 10 universities)

UNSW 2843




\begin{tabular}{|ll}
\hline Curtin & 1749 \\
Monash & 1654 \\
RMIney & 1515 \\
Melbourne & 1398 \\
Queensland & 1395 \\
Sth Queensland & 1152 \\
WA & 1046 \\
Wollongong & 993 \\
& 888 \\
& $\begin{array}{l}\text { Total of fee paying students = 16,800 } \\
\text { Total of overseas students } \\
1988=18,207 \\
1989=25,477 \\
1990=28,311\end{array}$
\end{tabular}

Nevertheless, despite the concentration of CCS/OS in certain disciplines and universities, this is not to say that all university staff do not come into contact with such students, or that the placement of such students is not spreading out to other Universities and disciplines. It does mean, however, that currently the main need for a positive response can be focused at those levels of study and in those discipline areas identified.

\section{What is The Nature of Difficulties Experienced by CCS/OS?}

The following statements are some of the comments offered by CCS/OS students concerning their problems during the course of their study:

- We suffered from a changed approach to learning. Here there is a need to know the theory first, then be able to apply it. This required us to adjust to a totally new situation.

- Here there was a need to look after oneself at all times.

- Here we need to take initiatives and to develop our own 
thoughts.

- We had been aware of many matters relating to our studies, of words and phrases and processes, but we had not heard the reasons for these matters before.

- We had been subject to an authoritarian approach to the delivery of information before, but now we are required to question everything.

- We had not been expected to perform as individuals before, but here we are asked to present seminars before peers and supervisors. This is like an enormous culture shock to us.

- Initially, we were confused in our courses here, but, at the same time we found it difficult to admit our confusion and to seek assistance.

- Our attitude to study tended to lack critically. We also lacked the ability to talk openly about a question, or to use references well.

Supervisors also made various observations about the problems the students were having in the cross cultural academic setting. Amongst these were the following:

- It seems wrong to leave the students without clear guidance in their studies, but, it was also wrong to over direct them.

- The students developed better in the company of other students or when they were placed under some degree of pressure.

- These students did not have a tradition of expressing criticism and found this difficult to do in the m setting.

- The students also had difficulty with analysing data, with expressing ideas in the culturally relevant linear mode, with their lack of background in reading literature surveys, and because they were always willing to agree.

\section{Language Deficit Problems}

The most frequently heard observation from academics, concerning these students' language ability, was that even though they have passed the International English Language Testing Service (IELTS) test and have completed English learning programs, they still do not have adequate English to cope with the multiplicity of tasks of a university education. It would appear that their ability to cope with speed delivery, different accents. syntactical structures, vocabulary choice, idiomatic usage, nuances of meaning, different genres, ability to paraphrase and other areas 
of language are considerably limited

It might be observed here that irrespective of students being required to pass the IELTS test at a specified level, or some other form(s) of English language test, such students have still learned English as a foreign language. This usually means that the student uses English quite laboriously and with a considerable degree of uncertainty.

It is apparent that even if the student graduated from the IELTS testing at the required level, which for some universities, is level 6 on a 9 point scale, this cannot assure staff of the type of quality of language fluency they require. This ability is considerably different from "9 Expert User”, or "8 Very Good User”, or "7 Good User”. ${ }^{10}$ But if consideration is given to increasing or reducing the IELTS level, a balance needs to be arrived at between a level which will not prevent the majority of applicants from reaching Australia and collapsing the Full Fee Paying policy initiative, and the understanding that perhaps language proficiency is only one of the factors contributing to study success. ${ }^{11}$

Staff should also bear in mind that English language programs, conducted under the name of English Language Intensive Courses for Overseas Student (ELICOS), no matter how thorough, can only do so much to develop the students' language abilities. It takes a considerable time for second language proficiency to develop. ${ }^{12}$ It is also important to realise that the further students progress in their studies the more each student will require individual, specialised assistance. To this is added the specialised language requirements of each discipline. One lecturer in Engineering noted that the "there are 5 departments within Engineering." It might be asked, therefore, how can ELICOS staff cope with the various language requirements of these diverse areas?

It is possible that presessional English courses and English language testing procedures have reached their optimum efficiency in their capacity to assist students develop their language proficiency levels. Therefore, if universities continue to market their courses overseas and to enthusiastically encourage students to study in Australia, perhaps the time has come for academic staff to be assisted to become sensitive to the dynamics of language communication. This requires an awareness of one's own use of language, an awareness of the language of one's subject area and an 
awareness of the language abilities and limitations of one's audience.

\section{Teaching Style Differences}

Apart from the problems CCS/OS students experience with the English language, the current research findings indicate that CCS/OS also have considerable difficulties coping with the teaching styles and assessment processes of Australian universities. For instance, they seek to take verbatim notes. They are confused by the rapidity of delivery and by the ideational density of the content. It is unusual for them to have attended tutorials or to have given oral presentation before, to name but a few problems. Also, little if anything, it would seem, has prepared the CCS/OS for the complexities of the way they are to be assessed.

In general, it would appear, students from Asian countries have been used to a style of teaching which included the deliberate and authoritative provision of information, information which they are expected to learn and repeat at the end of year examination. Also, lecturing staff are generally the object of considerable respect and resources are scarce.

Tables 5 and 6 give examples of some differences between Asian and Australian styles of education.

It would seem to be critical, therefore, that staff develop an awareness of the styles of teaching and assessment which such students have experienced. It would also seem to be necessary that staff develop a sensitivity to their own teaching and assessment styles and their impact on cross cultural and overseas students.

Table 5: Typical Differences between Asian and Australian

\section{Teaching Styles}

\section{ASIAN}

Main vehicle of teaching is the lecture which is paced and clear.

Argumentation is not encouraged.

Considerable amounts of information are presented.

\section{AUSTRALIAN}

Academics use lectures, tutorials, practicals, computers, libraries, interviews, field trips, etc.

Staff expect a students to debate.

Summaries of the state of the art are presented. 
Staff do not assume that other sources of information are available.

Information is presented gradually.

Equipment is used sparingly.

Students have had little research experience.

Students work under close supervision.

Little opportunity to ask questions in teaching sessions.
Staff expect students to read in the libraries.

By comparison, three times as much information is presented in the same period.

Equipment is used regularly.

Students have been exposed to a research approach since primary school.

Students are expected to take initiatives.

Constant opportunity is given to ask questions in all forms of teaching.

Table 6: Typical Differences between Asian and Australian Assessment Styles

\begin{tabular}{|ll|}
\hline $\begin{array}{l}\text { ASIAN } \\
\text { Year end exams are the normal }\end{array}$ & $\begin{array}{l}\text { AUSTRALIAN } \\
\text { Term/semester exams are only one } \\
\text { of the forms of assessment. Other } \\
\text { forms are assignment, field trips, } \\
\text { tute papers, practicals, orals and } \\
\text { seminars. }\end{array}$ \\
$\begin{array}{ll}\text { Multiple choice questions format } \\
\text { is the usual mode of questions. }\end{array}$ & $\begin{array}{l}\text { Exams are usually characterised } \\
\text { by challenging questions and } \\
\text { require an essay response. } \\
\text { Technical language is sometimes } \\
\text { required. }\end{array}$ \\
$\begin{array}{l}\text { Questions usually require content } \\
\text { material already presented in } \\
\text { lectures. }\end{array}$ & $\begin{array}{l}\text { Questions require critical } \\
\text { applications of information, only } \\
\text { some of which has been presented } \\
\text { by staff. }\end{array}$ \\
$\begin{array}{l}\text { Normal expectation is that if one } \\
\text { attends lectures and puts in effort } \\
\text { one will pass the examination. }\end{array}$ & $\begin{array}{l}\text { Attendance at lectures not required } \\
\text { and does not mean success in the } \\
\text { examination. }\end{array}$ \\
The style of writing differs from & One must know theory and be able
\end{tabular}


Western prose.

It is not necessary to be able to select questions well. to express it clearly and logically.

It is not necessary to select questions well. This necessitates an ability to read quickly and well.

\section{Learning Style Differences}

The majority of cross cultural/overseas students become aware that there is a difference in the way that they are expected to acquire and understand information in Australia. Initially, they might describe Australian students as "lazy", or to consider that they worked harder in their own countries, but students with more insight say such things as "here we must lean the theory first, then the practice" or "we must take initiatives."

Many of these students express a positive opinion about the freedom from an authoritarian approach and appreciate the freedom they have to criticise and debate issues with peers and superiors. But this appreciation only comes with prolonged experience in Australia. Table 7 gives examples and comparisons of the learning styles differences between cultures.

Table 7: A Comparison of Typical Asian and Australian Learning Styles

\section{ASIAN}

Rote learning is common.

Non-critical reception of information is expected.

Students work hard to learn everything.

Students are disinclined to seek clarification.

Few initiatives are taken.

A willingness to accept one interpretation.

\section{AUSTRALIAN}

Evaluative learning is preferred.

Critical thought is expected

Students selectively learn the central concepts as well as detail.

Students are willing to seek assistance as part of the learning process.

Independent learning and research are rewarded.

Students encouraged to apply general principles to specific situation and to test various interpretations. 


\section{Cognitive Style Difference}

The term Cognitive Style is used to describe the given, relatively unchangeable disposition of an individual to carry out mental processing in a particular characteristic way. ${ }^{13}$ Baecher described cognitive style in the following ways:

It is the way the student tends to seek for meaning. It develops as the individual interacts with other members of the community and with the education system. Throughout this experience the student comes to prefer certain ways of acquiring meaning from the world. The importance of the information is then determined on the basis of cultural determinants, such as, the importance of the individual's own opinion, or on the basis of the associates of the individual, or on the basis of the opinion of the family. Finally, there is the ability of the individual to assess the importance of the information as a result of the individual's modality of inference i.e. whether the individual prefers to consider the information on the basis of given norms before accepting or rejecting it; that is, whether the information needs to be compared and contrasted; whether the individual attempts to synthesize the information into a unified meaning, or to discover its component parts; whether the individual prefers to reason deductively about the information, or to seek logical proof and to make conclusions. As a result of such preferences, the student may become a listener, a reader, a person who seeks the opinion of others, or one who prefers to study alone.

By making a comparison of the material which arose from the study with the description of Cognitive Style as outlined by Baecher and Willing, ${ }^{14}$ it is also possible to conclude that the CCS/OS students approached university study in Australia with a different cognitive style to that expected.

Given the authenticity of this conclusion, it is also possible that the students' cognitive approach to learning was characterised by other features of cognitive styles as identified in the literature. ${ }^{15}$

Studies also indicate that an understanding of the hemispheric workings of the brain might be important in considering different cognitive styles. The individual may prefer to reason on the basis of the one rather than the other, or may use either on different 
occasions.

For Asian students attending Australian universities, if rote learning has been highly rewarded in their home culture they may successfully learn lecture notes off by heart, but still do poorly in exams because of their failure to select critically the material required to develop a theme or answer a question.

\section{The Need for Training for Change}

The above material indicates that it is an opportune time for academic staff to realise that no longer can it be argued that all the difficulties can be solved by getting the students to change; for them to learn more English; for them to cope with the new learning situation. Rather, the issue, for some departments might be for them to consider how they might change in order to facilitate a more empathetic learning environment for cross cultural and overseas students.

\section{The Nature of the Research Program}

The research program (1990-1991), reported on here, occurred in a period of dynamic change in university education with respect to the increase in the intake of full fee paying overseas and cross cultural students. The project sought to investigate:

- the nature of the reaction of academics to the overseas and cross cultural students attending their courses;

- define the nature of this new reality;

- identify and classify the types of difficulties which both academics and students are experiencing, and

- describe the positive changes which staff and students are implementing in order to cope with the challenges of academic life in the 1990s.

Other Australian studies, such as those carried out by Bradley and Bradley ${ }^{16}$ and Ballard and Clanchy ${ }^{17}$ tend to identify similar difficulties faced by CCS/OS and academics. These difficulties tend to be long standing and ongoing.

The results of the 1984/85 and 1990/91 studies indicated that when academic staff were sensitive and responsive to the cross cultural nature of the students, this tended to improve the results the students obtained. ${ }^{18}$ 


\section{The Code of Ethical Practice}

In response to the university sector entrepreneurial initiative the Australian Vice Chancellor's Committee (AVCC) issued a Code of Ethical Practice to which all co-operating institutes must agree. This code seeks to ensure:

that the potential benefits of full-fee paying overseas students who choose to study in Australia are fully realised for both the students and the host institutions ${ }^{19}$ and that a commitment be given based on the premise of "value for money"20

Further, that such a commitment include:

consistent and caring procedures in the recruitment, reception, education and welfare of overseas students. ${ }^{21}$

Other requirements include a commitment to

the maintenance of academic standards in Australian institutions.

The document also emphasises the need for staff development in responding to such students. It states that institutions should encourage a supportive environment by:

promoting understanding amongst staff of the special social and cultural need, including dietary and religious requirement. ${ }^{23}$

This document also calls for the development of "training programs appropriate to the different levels of involvement and responsibility among staff". ${ }^{24}$ The findings of these research projects would call into question whether the requirements of the Code are being implemented by the participating institutions.

\section{STAFF CONCERNS}

The current research has found that a large number of academic staff are concerned over many matters related to the new initiative and the new type of student body. For instance:

- They believe that a significant number of overseas students are getting through to university study with inadequate English proficiency, and that this might mean that they would not be able to cope with the university studies in Australia. Staff express the opinion that students should develop their English before coming to Australia and be encourage to change to fit the university setting. 
- They believe that many sympathetic academic staff are going to unusual lengths to ensure that overseas students succeed in their studies, with a few actually writing theses for students. Others also find that the time demands on them have increased dramatically.

- Staff have complained that student numbers have increased but the number of staff members has stayed the same.

- Staff are concerned that the financial gains which have come from fees have not benefited those who primarily carry the extra load of teaching, but have sometimes been taken-up by more senior staff administrators.

- Finally, staff have suggested that many of them were never trained to teach in the first place and now the teaching setting is even more complex.

\section{THE NEW REALITY}

Nevertheless, irrespective of the complaints, shortcomings and problems, there is a new reality. The nature of the student population has changed and large sections of the university system could not survive without financial support of full fee paying students. On the other hand, it would appear that many academics have not changed their approach to the new type of student and many even question whether they need to change.

\section{Why Should Academics Change?}

It is justifiable for academic staff to question the need for changes in their response to cross cultural and overseas students. After all, they may argue that these students come here to get Australian degrees.

\section{Academic Adjustment to CCS/OS}

The central dilemma, therefore, faced by universities institutions and the staff who supervise, teach and examine overseas students is as follows: given the desire to maintain the authenticity of the university degree and yet at the same time be able to respond to the nature of the new type of cross cultural and overseas students, who are increasingly attending universities, what, if any, should be the nature of adjustment by the institution 
and its academic staff to these students?

For many academics it is a new experience to have CCS/OS in their classes and they face many dilemmas. These include: whether they should alter their styles of teaching; whether they should alter their styles of speaking; whether they should alter their styles of assessing, or whether they should adjust their courses. Another dilemma is centred on the economics of "encourage(ing) a high success rate" 25 in overseas student studies. The question seems to be whether academics should insist that overseas students meet the same standards maintained and applied to local students, even though this action might result in student failure and the loss of funds coming from overseas students, or should there be a hidden curriculum for overseas students, whereby sufficient reductions of standards are made, so that such students pass their courses and consequently, overseas student funds are preserved?

It is a hidden curriculum because it is realised that overseas countries insist on their students acquiring the same qualifications as local Australian students. Should they suspect that standards have been adjusted, they might place their students elsewhere.

This dilemma arises initially from the academic's desire to provide the most effective course for the students. While the second aspect of the dilemma is driven by the academic-bureaucrat wanting to safeguard programs and consequently jobs.

It is important that both the home community and overseas countries continue to value university institutions for the quality of the degrees offered. Consequently, each institution guards its awards and thereby its reputation with diligence and concern and view any changes to their courses, or to the way they are taught, with suspicion.

In reality, however, academic awareness that overseas students generally have insufficient English, frequently have lower levels of pre-tertiary education and different post study objectives to Australian students has resulted in some institutions and staff reacting to such students quite differently to local students. Sometimes these reactions are of a negative nature, while at other times they are of a positive nature. The 1984/85 and the 1990/91 studies have indicated that these reactions have a direct effect on these students' academic results. ${ }^{26}$ 


\section{Academic Staff Response}

The following section presents a discussion of the nature of the adjustments made by academic staff of the universities to the CCS/OS post-graduate and undergraduate students observed in these studies. This discussion is based on the courses observed, discussions with the students, and discussions with the staff concerned. It cannot, however, be said to represent the reaction of the institution, since it is a report on the observed, actual adjustments made, rather than on the published university statements on the subject.

It should be added here that all the staff of the institutions observed were concerned to maintain the quality of the awards which were offered to the students. The staff differed markedly, however, in how they went about doing this and how they reacted to the CCS/OS students.

\section{The Sympathetic Register}

The research observations made during the Australian International Development Assistance Bureau and Department of Employment, Education and Training sponsored studies clearly identified that the nature of the interaction between certain academics and their CCS/OS students differed to marked degree from that of other academics. These activities might be described as types of adjustments to their style of interaction with students because of the staff members' awareness of the different types of students they were teaching.

It was also apparent that the nature of this interaction had some considerable bearing on the results the students received at the end of the semester or year. These adjustments by university academic staff, or the lack of such adjustments, were seen as composites of some type of academic environment, or framework in which the students studied. An environment which might be described as either positive or negative in relation to its inducement to study outcomes.

From an analysis of the observations made during both research projects it was possible to identify four main types of major categories within which certain types of adjustments towards CCS/OS were occurring. These were identified as follows: 
Empathetic Adjustment; Course Adjustment; Supervision Adjustment, and Adjustment Stemming from Prior Contact. These categories were grouped together to make up what is referred to here as a Sympathetic Register.

Each of the four categories was arrived at as a result of discussion with students and staff and from observations of the academic staff. The categories tend to overlap in certain respects, but in general they concur with the researcher's intuitive reactions to the data collected.

The author realises that underlying this descriptive tool there is a general type of value system, but more objectively it was found to have a degree of worth, especially when consideration was given to the nature of predicting whether students would do well in their studies dependent on the results in various language tests.

In the 1984/85 study it was found that students who performed well on language proficiency tests, but who subsequently studied in what is described here as a negative learning environment tended to perform poorly, and vice versa, students who performed poorly on language proficiency tests and then studied in a sympathetic environment tended to perform well in their academic studies.

It should be noted here that due to the highly sensitive nature of this aspect of the study, a naturalistic approach, rather than an empirical approach was used to gather the data which supported the resolution of the Sympathetic Register.

\section{The Evaluation Profile}

In order to assess either the positive or negative nature of the academic environment, each of the four categories of the Register was assessed on a five point scale. One represented a negative degree of adjustment, and five represented a positive degree of adjustment. By noting the numeral profile given for a particular environment it was possible to build up a reasonably clear profile of that academic setting. For instance, a 2321 profile indicated some type of negative learning environment was occurring, while a 4554 indicated a positive environment existed. Correspondingly, staff who were associated with a 2321 type of environment might be described as LOW EMPATHY STAFF, or staff who manifested various low levels of response to either the students' language and cultural background, or who failed to make any adjustment to the 
content or requirements of their course, or staff who failed to modify in any positive way how they supervised such students, and finally staff who had little if any overseas experience on which to base any modifications to their courses. Staff associated with a 4554 type of environment might be described as HIGH EMPATHY STAFF. Such staff were judged to have reacted quite positively with respect to the above categories.

The Sympathetic Register, developed by the author, proved to be a useful classifactory mechanism to enable the researchers to gain some understanding of the academic environment in which the students studied.

\section{Pre-university Study Language Assessment Performance}

Nevertheless, the value of this particular aspect of the study may only be fully appreciated if consideration is given to the level of English language proficiency attained by these students' prior to their entry into Australian university studies (see Table 8). Seventy six students had attended a six month English language training course before beginning their university studies and during that process were continuously assessed for language proficiency.

Up to five language tests were administered to most of the students prior to their arrival at an Australian university. The test results for 14 of the students are presented in Table 8 . This table also includes a category detailing the nature of the predictions of language teaching staff on whether they thought such students would be successful in their university studies and also details whether or not the students passed or failed their first year of university studies, and finally, it introduces the categories of the Sympathetic Register. 
TABLE 8

\begin{tabular}{|c|c|c|c|c|c|c|c|c|c|c|c|c|}
\hline \multirow[b]{2}{*}{ Student } & \multicolumn{5}{|c|}{ Language Test Results } & \multicolumn{2}{|c|}{ Staff Predictions } & \multirow{2}{*}{$\begin{array}{c}\text { University } \\
\text { Study Results }\end{array}$} & \multicolumn{4}{|c|}{ Sympathetic Register } \\
\hline & Pre-test & Post-test & Pre-test & Post-text & ASLPR & ALC & EPC & & $\mathrm{A}$ & $\mathrm{B}$ & $\mathrm{C}$ & $\mathrm{D}$ \\
\hline 1 & $\mathrm{~F}$ & $\mathrm{~F}$ & $\mathrm{C}$ & $\mathrm{F}$ & YES & NO & PASS & 5 & 3 & 4 & 5 & \\
\hline 2 & $\mathrm{D}$ & B & $\mathrm{C}$ & C & LOW & YES & YES & PASS & 5 & 3 & 4 & 5 \\
\hline 3 & $\mathrm{~F}$ & $\mathrm{~F}$ & C & $\mathrm{F}$ & LOW & NO & NO & PASS & 3 & 4 & 3 & 4 \\
\hline 4 & $\mathrm{~F}$ & D & C & $\mathrm{F}$ & & YES & NO & PASS & 4 & 5 & 4 & 5 \\
\hline 5 & $\mathrm{~F}$ & $\mathrm{~F}$ & C & $\mathrm{F}$ & & YES & NO & PASS & 3 & 4 & 3 & 4 \\
\hline 6 & $\mathrm{~F}$ & $\mathrm{~F}$ & $\mathrm{C}$ & $\mathrm{F}$ & LOW & NO & NO & PASS & 2 & 3 & 4 & 2 \\
\hline 7 & D & B & B & B & MID & YES & YES & FAIL & 1 & 2 & 3 & 1 \\
\hline 8 & D & B & B & & & YES & & FAIL & 1 & 2 & 3 & 2 \\
\hline 9 & $\mathrm{~F}$ & $\mathrm{~F}$ & B & $\mathrm{F}$ & MID & YES & YES & FAIL & 1 & 2 & 1 & 1 \\
\hline 10 & $\mathrm{~F}$ & B & B & $\mathrm{F}$ & MID & YES & NO & FAIL & 4 & 2 & 3 & 2 \\
\hline 11 & $\mathrm{~F}$ & $\mathrm{~F}$ & $\mathrm{C}$ & $\mathrm{F}$ & MID & YES & NO & PASS & 5 & 5 & 5 & 5 \\
\hline 12 & $\mathrm{~F}$ & $\mathrm{D}$ & & $\mathrm{F}$ & & YES & & PASS & 4 & 3 & 3 & 4 \\
\hline 13 & $\mathrm{~F}$ & D & A & B & & YES & YES & FAIL & 1 & 1 & 1 & 1 \\
\hline 14 & $\mathrm{~F}$ & B & & B & & YES & & FAIL & 1 & 1 & 1 & 1 \\
\hline
\end{tabular}

Abbreviations: Language test results have been classified on an A to F basis, with A representing excellence and F representing a fail result.

The ASLPR test used was a test which indicated a high, medium or low level of general English proficiency.

Under Staff Predictions, the first column presents the predictions of staff from the Australian Language Centre in Jakarta. The second column presents the predictions of staff from the English Preparation Centre in Sydney. Staff were requested to attempt to predict whether or not the students would be successful in the first year of university study. The use of Yes or No indicates whether teaching staff generally agreed that the student would succeed in future university study or not. 
Under Uni Study Results, a PASS or FAIL means students passed or failed their first year of studies.

Finally, under Sympathetic Register the various numerals stand for grades within the four categories of the register. 
The inconsistency of the students' language test results and the predictions made by staff as to the students possible academic performance with the actual end of year academic results are evident. On the other hand, a comparison of the students' first year results with the classifications of the Sympathetic Register indicate some considerable degree of consistency.

\section{The Four Categories of the Register}

The Sympathetic Register was divided into four categories to account for some of the different types of activities observed.

Category 1, EMPATHETIC ADJUSTMENT, was defined by the degree of adjustment made by academic staff towards the CCS/OS students' NEEDS in the light of their language and cultural background. A positive degree of adjustment was of the nature of promoting maximum success by students to the demands of the institutions.

Category 2, COURSE ADJUSTMENT, was defined as the degree of adjustment made towards the students' country of origin and needs in respect to the overall study package and the content of the units. A positive degree of adjustment was of the nature of making various changes to the course which took into account the students' background and future work locations.

Category 3, SUPERVISION ADJUSTMENT, was defined on the basis of the nature of the contact offered by supervisors. ie, were supervisors

- nurturing, close, accessible, informed as to the students' cultural, linguistic, educational and academic background?

- able to apply such knowledge to facilitate the students' learning experience?

- willing and able to adjust the requirements of the course to suit the students' needs or,

- able to permit the students' to take initiatives when the students proved able to take them?

Category 4, ADJUSTMENT STEMMING FROM PRIOR CONTACT, was defined on the basis of the degree of experience such supervisors and or departments had of overseas countries. In general, the study found that the more prior association staff had with these students or with an overseas experience the more suitable were the programs they offered to such students. 
Nevertheless, there were cases where this was not the finding.

\section{Examples of the Four Categories}

(1) Empathetic adjustment by university staff members to the overseas students has been defined on the basis of the degree of adjustment made towards the students' academic needs in the light of their language and cultural background. This adjustment involves promoting maximum success by the students vis-a-vis to the demands made by the institutions. The following is a list of activities which were observed to be more or less empathetic.

(a) When staff appreciated the students' cultural background, some supervisors sought out the students and encouraged them to attend interviews and to set up meeting schedules and other contacts. Other staff simply waited, in some cases for up to two terms, for the student to approach them for assistance or to make an appointment. Some students were hesitant to approach the supervisor due to their fear of approaching people in authority.

(b) To assist students to overcome language problems, some staff took extra time to explain matters and to discuss issues. Other staff presented materials and expected students to ask other students or to search out the matters in the literature. Some students were observed to spend up to a day simply to find one textbook to avoid bothering the supervisor.

(c) On the basis that post-graduate second-language students tend to improve their language abilities over the first year, examination results were interpreted as being merely indicators of the students' ongoing progress. Other staff considered them to be crucial in determining whether students should proceed further.

(d) Some staff, acknowledging the students' inadequate English language ability, merely expected the students to express themselves in reasonable English. Other staff required exact English language expression. This was particularly noticeable in Humanities.

(e) In order to give students time to translate from English to their own language and back to English, some staff extended the time limit on examinations. Other staff did not allow for this and imposed the required time period. 
(f) In order to assist students with abstract English concepts some staff were prepared to be less theoretical and more practical in presentation. Other staff continued to present most information in a strictly language format.

(g) Some staff attempted to overcome the problem the students were having with their accents by speaking more clearly, while others spoke quickly with a difficult accent, yet nevertheless, imposed high assessment requirements on what they presented.

(h) Some staff realised that students were not used to the types of assessment procedures used in Australia, and therefore, either gave special instruction to assist the students or changed those assessment techniques. Other staff did not realise the problem and simply insisted on the normal Australian assessment procedures.

(i) Some staff gave out extensive handouts and used graphics to assist the students to understand their lectures during the first semester. Other staff took no account of these difficulties and expected the students to be able to cope with two or three hour long lectures.

(j) Some staff reduced the students' reading load because they realised that the students needed to read slowly in order to translate back into their native language. Other staff set a regular reading load for the students and expected them to keep up with Australian students.

(k) Some supervisors recognised their students' difficulties of coping with social problems and mixing with the wider Australian community. Other staff simply expected their students to cope with these difficulties.

(1) Some staff realised that students found it difficult initially to present oral seminars due to their cultural reticence to speak in front of supervisors. Other staff took no account of these concerns.

(m) Some staff realised that second-language learners find it difficult to cope with verbal interaction with Australians in and outside the university, so attempted to demonstrate how they might accomplish this. Others tended to play no part in this level of communication.

(n) Some staff realised their students had difficulty with taking 
notes and spent time preparing students for lectures or gave them either extensive notes on the lecture or outlines of what was presented. Other staff presumed students were able to write quickly and to concentrate on what was being presented.

(o) Some staff realised that their students were hesitant to seek feedback, and so went out of their way to give adequate feedback. On the other hand, many staff gave little if any feedback and even confused the students by giving misleading feedback, such as comments without a grade on the paper.

(p) Some supervisors realised that direct questioning techniques may be offensive to the students and so devised strategies, such as having the students present written pieces of work first, to be followed by discussion. The material was then the focus of discussion.

(q) There are staff who realised that these students tended to learn differently from Australian students and who, therefore, introduced activities to assist them to adjust to the Australian learning styles. These included problem solving, careful reading activities, avoidance of straight memorisation, the provision of foundational knowledge, and careful guidance throughout projects. These were given to enable students to gain a solid knowledge of the field and to apply such knowledge in their home countries.

(r) Some supervisors were willing to change their approach when they discovered that what they were doing was not appropriate for these students. For instance, some found that calling students out to the front to present a talk, or asking students to answer direct questions, such as responding to questions about this or that problem, to be ineffective. These practices were changes to focus on an activity or a written piece of work.

(s) There were staff who realised that the students' body language, such as blinking, or nodding, did not necessarily mean that the students understood the message and that the staff member should continue with the explanation. On the other hand, some staff misunderstood these indications to mean that the student understood, and so went on to the next point. 
(t) Some supervisors were willing to assist students to learn how to express themselves in the logical, linear patterns required, and to overcome their tendency to express themselves in repertoires of remembered utterance.

(u) Some supervisors permitted students to bring books into examinations in order to assist them to overcome the problems of attempting to remember certain language- based matters in a second language.

(v) Some staff saw it as important to present guides for discussion ahead of time so as to assist the students to prepare their language and their minds.

(w) Some staff went out of their way to ensure that the students were given every opportunity to pass the course whereas other staff, who imposed requirements as for Australian students, offered the students the opportunity to use the appeals system. In such cases, it was obviously not realised that such a system would be quite strange to the students.

(x) Some staff attempted to assist their students with their problems by introducing a computer literacy course. After this course, the students were able to type their assignments on the computer. The staff member them applied a Speller Corrector program to the essay, so that it began to appear more like English. Final work was then done on the syntax of the essay.

\section{(2) Course Adjustment}

Course adjustment had been defined as the degree of adjustment in course content made towards the students' country of origin interests. This adjustment was made both with respect to content of the units and the overall study package.

This study identified the ideal program for these students during the first year as one which was oriented mainly towards research, but which also included some undergraduate subjects, and one in which examination assessment was experienced, but was not over weighted. The researchers observed the following types of course adjustment:

(a) Some courses, for postgraduate students, were carefully designed to give the students necessary background information, but were also postgraduate in nature. Other 
courses, for postgraduate students, were focused on first and second year undergraduate units. Although the latter apparently contained useful information which post graduate students should understand, they required the students to study with undergraduates, to complete exhaustive assignment and examination work and, above all, to cope with extensive language demands for which many of them were not prepared. These types of courses proved to be very demanding.

In general, the research indicated that undergraduate courses are far more demanding on CCS/OS due mainly to the need for students to cope with the wide variety of language demands in these courses.

(b) Some courses were virtually designed on the spot for postgraduate students in the light of their requirements. Other staff took no account of the specific needs of the students.

(c) Where the course was comprised mainly of undergraduate units, contact with the supervisor was usually reduced. This proved to be unsatisfactory. Several supervisors, therefore, reduced unit-oriented studies and focused the student more on the Masters level work. Students were still permitted to monitor undergraduate units, and were even assisted to do so, but the heavy assignment and assessment load were not required. This generally resulted in a better study program for the student.

(d) Some supervisors introduced a degree of research work from the beginning and did not wait until the student was "ready". The majority, however, insisted that the research work should take place primarily in the second year.

It is apparent that research should be carried out into these different approaches to assess which is the most effective from the students' point of view.

(e) While many supervisors attempted to make clear what assessment meant, and what was required for the student to proceed to the second year of studies, some staff had problems resolving this matter, either for themselves or for the student. The results of this indecision were quite negative.

(f) In some cases the content of the course was closely related to what the student had been studying, or working on in their 
home country. The results of these programs were highly beneficial to the student.

(g) Some staff made special arrangements for students to take introductory courses in such areas as computing, statistics and research methods to assist them to understand these new areas. Other staff expected the students to cope with computer terminology and technology from the outset of their course.

(h) Some staff expected that if the students got through the first year, of the first semester, they would be successful in their second period. Other staff had doubts that students would succeed at any time. This negative attitude tended to become a self fulfilling prophecy.

(i) Some departments permitted staff to adjust to the study requirements of students. Other departments imposed strict requirements of the rules of the institution.

(j) Some staff conducted courses which were well designed and had appropriate assessment loads. Others offered courses which had too many lecturers to identify with, used assessment which was too varied, had too many different typed of requirements, and which in general, left the students confused, overworked and unhappy, even apart from considerations of the content of the courses.

(k) In a number of study programs staff attempted to frighten the students into working harder and insisted that they would have to pass the units at a Credit or Honours 2A, level if they wanted to progress to the next term's work. In fact, students tended to be excessively frightened by these demands because of their concern about returning home a failure. This in itself had a negative effect on student activity. Other staff realised that the students generally worked harder than local students and sought to overcome their study problems by modifying the course requirements.

\section{(3) Supervision Adjustment}

Supervision adjustment towards the CCS/OS students was defined as supervision which was: nurturing, close, accessible; informed as the students' cultural, linguistic. educational and academic background; able to apply such knowledge to facilitate the students' learning experience; willing and able to adjust the 
requirements of courses and the content of the courses to suit the students' needs, and able to permit the students to take initiatives when the students proved able to do so.

These studies found that, in general, students were unable to cope with a high degree of independent study and required close supervision during the first year. On the other hand, the study found that many institutions offered only light supervision for the students during the first year, and then would increase this considerably during the second year. This practice was found to be unsuitable for the CCS/OS students.

The following information represents a description of the observed supervisor reaction to the CCS/OS postgraduate students. It needs to be emphasised that the writer refers here to the institutions' or the lecturers' willingness to help the students adjust to the demands of the institution and not to their willingness to lower the course requirements or their expectation of their students' performance.

The researchers observed the following:

(a) Some supervisors were sociable and accessible, while others were constantly difficult to locate or were overseas for considerable periods.

(b) Some supervisors were able to respond to many of the background factors of the students' lives and were open to change, and to the special study and course requirements of the students. Others appeared not to know the background of the students, or were unwilling to adjust courses for them.

(c) Some staff went out of their way to seek out and to set up appointments for students. rather than expecting them to initiate such sessions. Others simply waited in their offices for students to approach them.

(d) Some supervisors were quite knowledgeable about their students' past and future work situation so that they could adjust courses to suit students' needs, even to the extent of purchasing equipment for the students to take with them on their return to their home country. Other staff not only did not know this information, but were also not willing, or unconcerned, to permit it to make any difference in the program set for the students.

(e) Some supervisors went out of their way to treat the students 
as adult postgraduate students, while there were other staff who were quite impersonal and even avoided students.

\section{(4) Adjustment Stemming from Prior Contact}

Adjustment following prior contact was defined as that information gained by individuals or departments from prior contact with overseas countries, which resulted in some type of positive reaction to the students. This study found, in general that, where departments or individuals associated with the students had overseas experience, the programs they identified for study in Australia, and the ways staff interacted with the students were usually more suitable.

The researchers observed the following:

(a) Some supervisors were familiar with the home locations and institutions of students.

(b) Some staff had personally selected the students for higher studies and, therefore, were able to adequately meet their requirements.

(c) Some staff, although they had not been to students' specific country, had been to other counties and had seen it as their responsibility to provide the support services the students would need.

(d) Some staff were keen to visit the countries of origin of the students and to make their programs more suitable. Some also planned to go to visit their students and to assist them further in their work.

(e) On the other hand, there were staff who had none of this type of background and who, although keen to visit overseas, at this time were unable to modify their programs in any informed way.

\section{The Effects of Academic Adjustment}

Of necessity, the researchers were restricted in the study to accepting the intellectual abilities of the students and to accepting that academic degrees in Australian university institutions have equivalent standards across institutions. Nevertheless, it was possible to consider similar degrees in various universities and to review them in the light of the Sympathetic Register ratings.

Where students had received similar grades on language tests 
prior to arriving at their university institutions and, thereafter, took similar university courses, a comparison of their first year study results indicated that their success was consistent with the nature of the academic environment in which they studied. A sympathetic environment generally meant success in their studies, while an unsympathetic environment usually resulted in a degree of failure. By using the Sympathetic Register, therefore, it was possible to compare the quality of one academic environment in which the student studied with another academic environment.

\section{Some Important Questions}

The study raised several important issues:

(a) If, in the 1984/85 study, the students' academic knowledge and English proficiency were shown to be quite low by the initial testing, and yet the large majority of students succeeded in their university studies at the end of their first year, then either the initial language assessment was incorrect, or a further factor which compensated for the students language weakness, had entered the picture. This factor seems to be the nature of the academic environment as measured by the Sympathetic Register.

(b) If there is a strong correlation between the Sympathetic Register and student study success, should this factor be given serious consideration by universities when they consider marketing their courses.

In other words, should universities give more attention to the training of their academic staff so that they are able to respond more empathetically to the CCS/OS?

This action would require upgrading staff knowledge about the countries of origin of the students, increasing staff knowledge of the language and cultural problems which students experience, exploring the possibilities of modifying courses so that they more adequately reflect the requirements of such students, providing staff with the information and training so that they can modify and improve their teaching and, amongst many other aspects, ensure that CCS/OS receive the ongoing support they need in order for them to successfully complete their course.

(c) Correspondingly, in the light of such findings, should 
language assessment and testing be given less prominence and be replaced instead by training students to handle specific academic environments? and/or placing the main emphasis on providing adequate receptor environments?

It would be appropriate, at this stage, to point out that Australian non-English background students (NESB) experience similar difficulties to those experienced by CCS/OS and, therefore, require the same type of sympathetic response from staff. Since NESB students constitute more than $16 \%$ of university students, their numbers would strengthen the argument for implementation of the above proposals.

To conclude, it is apparent that life in our universities has changed dramatically in the last decade. This is an exciting yet stressful time for all academic staff. We believe the key to coping constructively with this change is to actively explore alternative responses. The net results of improving the learning experience for overseas students will be an improvement in the quality of education for all Australian students. This study seeks to assist academic staff in making necessary adjustments to achieve this end.

* University of Canberra.

(C) 1992 (1992) 3 Legal Educ Rev 123.

1 Private correspondence with DEET.

2 Id.

3 This definition is a modified version of that used by EEO guidelines 1 \& 2 PSC, 1990 p.7 definition inserted by the Public Service Reform Act 1984 (Cth).

4 Supra note 2 and unpublished 1990 DEET material.

5 Id.

6 P Searle and E Brash, University Education of Overseas Agricultural Students (1990) 3 Agric Sci 36, at 37.

7 Id.

8 F Galbally, (Chair) A. Hams \& B Chapman Migrant Services and Programs (Canberra: AGPS, 1978).

9 Supra note 4.

10 International English Language Testing Service (Cambridge: Cambridge University, 1989) at 6.

11 D Phillips, E Burke, A Campbell \& D Ingram, The Evaluation Study of Preparatory English Language Training of Sponsored Indonesian Students: Find Report. (Canberra: Australian Development Assistance Bureau, 1985). This is a restricted document; D Phillips, Assessment for tertiary study: a consideration of the prominence given to language testing in selection of Indonesian students to study in Australia in Ethnicity and Cognitive Assessment: Australian Perspective (Darwin: Darwin Institute of Technology, 1988).

12 Id. 
13 R Baecher, Cognitive Style Mapping, in A Simoes ed, The Bilingual Child: Research and Analysis of existing educational themes (New York Academic Press, 1976).

14 K. Willing, Learning Styles in Adult Migrant Education (Adelaide: National Curriculum Resource Centre, 1988).

15 H Witkin \& D Goodwnough Cognitive Styles, Essence and Origins: Field Dependence and Field Independence (New York International Universities Press, 1981). R Coop \& K White, eds, Psychological Concepts in the Classroom (New York Harper and Row, 1974).

16 D Bradley \& M Bradley Problems of Asian Students in Australia (Canberra: AGPS, 1984).

17 B Ballard \& J Clanchy, Studying in Australia (Melbourne: Longman Cheshire, 1988).

18 D Phillips The Evaluation Study of Preparatory English Language Training of Sponsored Primary Determinants of Study Success of Post Graduate Indonesian Students in Australian University Institutions (Canberra: ADAB, 1985).

19 Australian Vice-chancellors Committee Code of Ethical Practice in the Provision of Full-Fee Courses to Overseas Students by Australian Higher Education Institutions (Canberra: AVCC, 1987) 1.

20 Id at $\mathrm{l}$.

21 Id at 1.

22 Id at 2.

23 Id at 8.

24 Id at 9.

25 Id at 2.

26 D Phillips, Academic Adjustment to Needs of Overseas Students (1988) January Babel 10. 